\title{
Liver X Receptors as potential therapeutic targets in atherosclerosis
}

\author{
Yanfei Zhu \\ Yousheng Li MD
}

\begin{abstract}
Nanjing University School of Medicine, Research Institute of General Surgery, Jinling Hospital, Nanjing, China
\end{abstract}

Manuscript submitted 28th July, 2009

Manuscript accepted 29th August, 2009

Clin Invest Med 2009; 32 (5): E383-E394.

\begin{abstract}
Purpose: Atherosclerosis is the primary independent risk factor of cardiovascular disease, and Liver X Receptor (LXR $\alpha$ and $\mathrm{LXR} \beta$ ) activation may play an antiatherosclerosis effect. In this article, we summarize the current state of knowledge of the roles of LXRs in physiology and homeostasis as well as the links between LXR action and atherosclerosis, and discuss the potential therapeutic effects of LXR agonists.

Source: A MEDLINE database search was performed to identify relevant articles using the keywords "liver $\mathrm{X}$ receptors", "LXRs", and "atherosclerosis". Additional papers were identified by a manual research of the references from the key articles.

Principle findings: Both LXR isoforms promote reverse cholesterol transport (RCT) and have anti-inflammatory activity. $\mathrm{LXR} \alpha$ is the predominant receptor in the liver regulating triglyceride synthesis. The antiatherosclerotic ability of LXRs makes them attractive targets for drugs for the treatment of cardiovascular disease. However, LXR activation induces lipogenesis and hypertriglyceridemia. The first-generation synthetic ligands of LXR increase hepatic lipogenesis and plasma triglyceride levels. New LXR ligands need to be designed without undesirable side effects.

Conclusion: LXR $\beta$-selective agonists and LXR modulators, which act as agonists in macrophages and induce cholesterol efflux while they are antagonists of lipogenesis in the liver, are two critical and attractive approaches to treat atherosclerosis and cardiovascular diseases.
\end{abstract}

\section{List of Abbreviations}

LXRs

LDL-C

HDL-C

AF

RXRs

DRs

LXREs

$\mathrm{N}-\mathrm{CoR}$

SMRT

HDACs

SRC-1

$\mathrm{NF}-\kappa \mathrm{B}$

PPARs

SREBR

HMG-CoA

FPP

SQS

$\mathrm{ABC}$

NPC1L1

RCT

PLTP
Liver X Receptors

Low-Density Lipoprotein Cholesterol

High-Density Lipoprotein Cholesterol

Activation Function

Retinoid X Receptors

Direct Repeats

LXR-responsive Elements

Nuclear Receptor Corepressor

Silencing Mediator of Retinoic Acid and Thyroid Hormone Receptor

Histone Deacetylases

Steroid Receptor Coactivator 1

Nuclear Factor $\kappa \mathrm{B}$

Peroxisome Proliferator-Activated Receptors

Sterol Regulatory Element-Binding Protein

Hydroxy-Methyl-Glutaryl Coenzyme A Farnesy1 Diphosphate

Squalene Synthase

ATP-Binging Cassette Transports

Niemann-Pick C1-Like 1

Reverse Cholesterol Transport

Phospholipid Transfer Protein 


$\begin{array}{ll}\text { CETP } & \text { Cholesterol Ester Transfer Protein } \\ \text { LPL } & \text { Lipoprotein Lipase } \\ \text { CYP7A } & \text { Cholesterol 7 } \alpha \text {-hydroxylase } \\ \text { FAS } & \text { Fatty Acid Synthase, } \\ \text { ACC } & \text { Acetyl-CoA Carbroxylase } \\ \text { SCD-1 } & \text { Stearoyl CoA Desaturase-1 } \\ \text { iNOS } & \text { inducible Nitric Oxide Synthase } \\ \text { COX-2 } & \text { Cyclooxygenase-2, } \\ \text { IL } & \text { Interleukin } \\ \text { MCP } & \text { Monocyte Chemoattractant Protein } \\ \text { TNF- } \alpha & \text { Tumor Necrosis Factor- } \alpha \\ \text { TLRs } & \text { Toll-Like Receptors } \\ \text { SMCs } & \text { smooth muscle cells } \\ \text { Skp2 } & \text { S phage Kinase-associated Protein 2 } \\ \text { SR-BI } & \text { the class B type I Scavenger Receptor }\end{array}$

cholesterol sensors and regulators of an array of genes associated with cholesterol synthesis, absorption, efflux and excretion, controlling whole body cholesterol homeostasis. ${ }^{5,6}$ They may also modulate inflammatory and proliferative responses in vascular cells and prevent the development of atherosclerosis. ${ }^{7,8}$ Nevertheless, synthetic LXR agonists may induce lipogenesis and then increase plasma triglyceride concentration and hepatic steatosis, considered an atherogenesis factor. ${ }^{9}$ It has been reported that LXR agonists can attenuate the development of atherosclerosis in spite of a potentially adverse lipogenic effect in mouse models. ${ }^{10-12}$ In this review, we summarize the biological roles of LXRs, the links between LXR action and atherosclerosis, and discuss the potential therapeutic effects of LXR agonists.

\section{Liver X Receptors}

and illness in developed and some developing countries. It has become the most widespread health problem worldwide, and atherosclerosis is the primary independent risk factor. ${ }^{1}$ Atherosclerosis is a chronic progressive disease characterized by the accumulation of lipids and fibrous elements in large arteries. Subsequently, the arterial wall gradually thickens to form an atherosclerotic plaque, which may rupture abruptly, resulting in myocardial infarction and stroke. Most notable risk factors include high levels of serum lowdensity lipoprotein cholesterol (LDL-C) and low levels of high-density lipoprotein cholesterol (HDL-C). Statins are highly effective lipid-lowering agents which can lower LDL-C by 24-61\%. However, many patients still experience adverse coronary events despite statin therapy, leading to the search for additional therapeutic intervention. ${ }^{1-3}$

Members of the nuclear hormone receptor superfamily play a critical role in metabolism, some of which can exert beneficial pleiotropic effects to reduce atherosclerosis and its complications. ${ }^{4}$ In particular, liver x receptors (LXRs) have been linked directly to the regulation of biochemical pathways involved in lipid homeostasis and inflammation. LXRs function as

\section{Molecular Structure and Distribution of LXRS}

The liver X receptors (LXR $\alpha$ and LXR $\beta$ ) are liganddependent transcriptional factors, belonging to the nuclear hormone receptor superfamily.,13 Their structure consists of: an N-terminal region containing a ligandindependent activation function (AF-1), a central DNA-binding domain containing two zinc fingers, a hydrophobic C-terminal ligand domain which mediates ligand recognition and receptor dimerization, and a ligand-dependent transcriptional activation function (AF-2). LXR $\alpha$ and LXR $\beta$ share a lever of cDNA homology of about $63 \%$, but differ in distribution. LXR $\alpha$ is highly expressed in liver (hence its name), and at lower levers in the intestine, macrophages, kidney and other organs, while LXR $\beta$ is expressed ubiquitously. 14-16

\section{Transcriptional Activities of LXRs}

LXRs function as heterodimers with the 9-cis retinoid $\mathrm{x}$ receptors (RXRs), then bind to specific DNA sequences consisting of direct repeats (DRs) of the core sequence AGGTCA separated by 4 nucleotides (DR- 
A. Active Repression

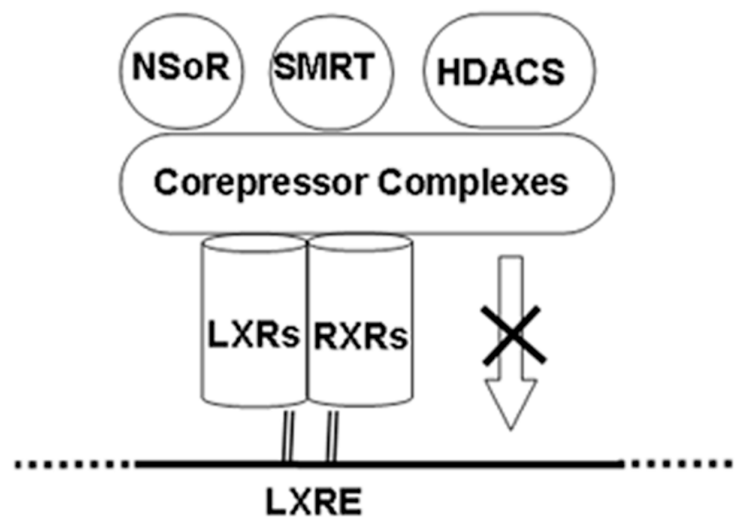

B. Ligand-dependent trans-activation SRC-1

\section{Coactivator Complexes}

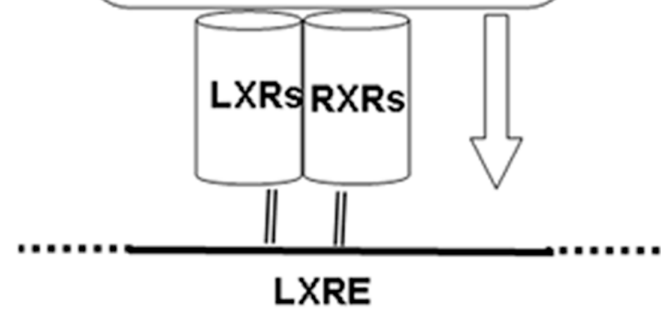

C. Ligand-dependent trans-repression
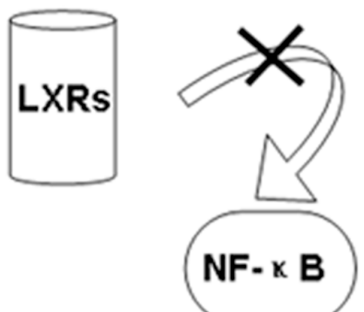

FIGURE 1. Transcriptional activities of LXRs

A: In the absence of ligands, LXR/RXR heterodimer can bind to target genes and actively repress transcription through the recruitment of corepressor complexes, including N-CoR, SMRT and HDACs.

$\mathrm{B}$ : Binding of a ligand induces a conformational change in the protein, leading to displacement of corepressors and the recruitment of coactivator proteins, such as SRC-1, then promotes transcription.

C: Ligand activation of LXRs can inhibit the activities of NF$\kappa \mathrm{B}$ which doesn't contain LXREs, this transrepression contributes to the anti-inflammatory ability of LXRs.
4), also known as LXR-responsive elements (LXREs) within the promoters of target genes. ${ }^{6}$ The heterodimer can be activated by either ligand of LXR and RXR. Experiments with N-terminal nuclear localization sequences mutant RXR confirmed that RXR may dominate the nuclear import of the LXR/ LXR $\alpha$ heterodimer, whereas LXR $\beta$ dominates the nuclear import of the LXR/ LXR $\beta$ heterodimer. ${ }^{14}$ LXRs regulate gene expression by at least via three different types of transcriptional activities (Fig 1). First, in the absence of ligands, LXR/RXR heterodimer can bind to target genes and actively repress transcription via the recruitment of corepressor complexes, including nuclear receptor corepressor $(\mathrm{N}-\mathrm{CoR})$, silencing mediator of retinoic acid and thyroid hormone receptor (SMRT) and histone deacetylases (HDACs). Second, binding of a ligand induces a conformational change in the protein, which leads to displacement of corepressors and results in the recruitment of coactivator proteins, such as steroid receptor coactivator 1 (SRC-1), then promotes the transcription of target genes. Third, ligand activation of LXRs can inhibit the activities of other signal-dependent transcription factors which don't contain LXREs, such as nuclear factor $\kappa \mathrm{B}(\mathrm{NF}$ $\kappa \mathrm{B})$. This activity, considered trans-repression, contributes to the anti-inflammatory ability of LXRs. ${ }^{1,6,15}$

\section{Ligands of LXRS}

Putative endogenous ligands of LXRs are oxidized cholesterol derivates (oxysterols). However, free cholesterol and cholesterol ester have no effects. The most important natural activators are 22(R)hydroxycholesterol, 20(S)-hydroxycholesterol, and 24(S),25-epoxycholesterol. In addition, D-glucose and D-glucose-6-phosphate have been identified as physiological agonists of both LXR isoforms. ${ }^{14}$ Most endogenous LXR ligands identified so far activate both LXR $\alpha$ and LXR $\beta$ except 25-diepoxycholesterol and 6a-hydroxy bile acids, which are somewhat selective for LXR $\alpha$. A number of pharmacological LXR ligands have also been synthesized. ${ }^{12,14,16}$ 


\section{Regulation of $L X R \alpha$}

The expression of LXR $\alpha$ is regulated by nuclear receptors, especially the peroxisome proliferatoractivated receptors (PPARs) and LXR $\alpha$ itself. In primary human macrophages, PPARs activation induces LXR $\alpha$, but not LXR $\beta$. Accordingly, oxidized lowdensity lipoproteins, which include agonists of PPARs, have been found to increase LXR $\alpha$ expression. ${ }^{17,18}$ Several studies have demonstrated the existence of an auto-up-regulatory loop controlling the expression of $\operatorname{LXR} \alpha$, but not LXR $\beta$. Interestingly, LXR $\alpha$ auto-up-regulation appeared to be limited to human cell types, and did not occur in murine macrophages or preadipocytes. This feature may be important during lipid loading of human macrophages, when LXR $\alpha$ is dramatically up-regulated and becomes the predominant LXR isoform, in contrast to the situation in resting macrophages. ${ }^{4,19}$

\section{LXRs and Lipid Metabolism}

\section{LXRs and Cholesterol Metabolism}

Cholesterol is a critical component of cell membranes and is the substrate for steroid hormone and bile acid synthesis. Cholesterol homeostasis is mainly maintained by balancing endogenous cholesterol synthesis, intestinal cholesterol absorption and reverse cholesterol transport with excretion of biliary cholesterol and bile acids (Fig 2). Because elevated cholesterol levels may relate to the development of atherosclerosis and cardiovascular diseases, so maintaining cholesterol homeostasis is very crucial. ${ }^{20,22,23}$

\section{LXRs and Cholesterol Synthesis}

In LXR $\alpha$-null mice, expression of the sterol regulatory element-binding protein-2 (SREBR-2), as well as Hydroxy-Methyl-Glutaryl Coenzyme A (HMGCoA) reductase and synthase, farnesyl diphosphate synthase (FPP synthase) and squalene synthase (SQS) were all increased. Smaller increases in the hepatic

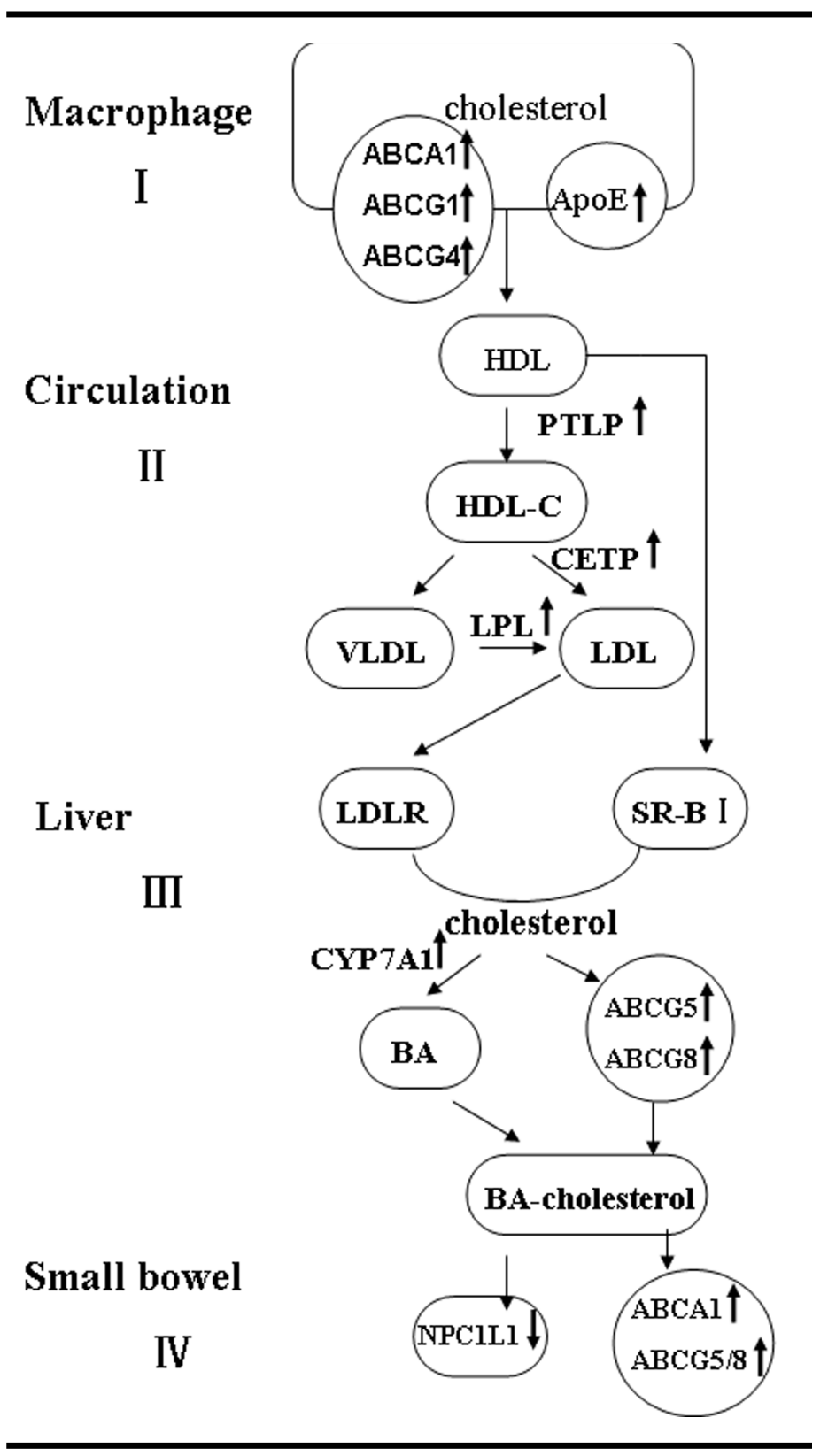

FIGURE 2. Role of LXRs in cholesterol homeostasis I. Macrophage phase: LXRs promote cholesterol efflux from macrophage via up-regulation of ABCA1, ABCG1, and ABCG4.

II. Circulation phase: LXRs promote maturation of HDL via up-regulation of PTLP, CETP and LDL.

III. Liver phase: HDL and LDL are taken up by liver through SR-BI and LDLR respectively. LXRs induce the expression of genes involved in the regulation of bile acid synthesis(CYP7A1) and cholesterol secretion(ABCG5 and ABCG8). IV. Small bowel phase: LXRs inhibit intestinal cholesterol absorption via up-regulation of $\mathrm{ABCA} 1$ and $\mathrm{ABCG} 5 / 8$ as well as down-regulation of NPC1L1. 
expression of HMG-CoA reductase, FPP synthase and SQS were also observed in LXR $\beta$-null mice, except SREBP-2.4,6 Consistently, the expression of these genes was markedly reduced following the administration of the LXR agonist T0901317 to wild-type mice. Current studies indicate that LXR $\alpha$ is a cholesterol synthesis inhibitor, directly inhibiting the expression of the lanosterol 14 $\alpha$-demethylase and SQS. ${ }^{24,25}$

\section{LXRs and Cholesterol Absorption}

Activation of LXRs by LXR agonists can reduce intestinal cholesterol absorption in mice. It appears to be primarily mediated through a transcriptional induction of a heterodimer consisting of two ATP-binging cassette transporters (ABC), ABCG5 and ABCG8, which are LXR target genes. These two proteins are an apical sterol export pump to promote active efflux of cholesterol from enterocytes back into the intestinal lumen for excretion. ${ }^{26,27}$

Niemann-Pick C1-Like 1 (NPC1L1) protein is a critical for intestinal cholesterol absorption. ${ }^{28}$ LXR activators down-regulate NPC1L1 mRNA levels in the human enterocyte cell line Caco-2/TC7. Furthermore, NPC1L1 mRNA levels are decreased in vivo, in duodenum of mice treated with the LXR agonist T0901317. Therefore, LXR activation inhibits intestinal cholesterol absorption. ${ }^{29,30}$

\section{LXRs and Reverse Cholesterol Transport}

The RCT system actively transports excess cholesterol from lipid-loaded cells back to the liver for secretion into the bile. LXRs regulate all the major steps of RCT through several potential mechanisms. ${ }^{31}$ First, LXRs induce the expression of several ABC transporters in macrophages, including $\mathrm{ABCA} 1, \mathrm{ABCG} 1$ and $\mathrm{ABCG} 4$, thus facilitating cholesterol efflux from the cell membrane to its extracellular acceptors, such as apolipoproteins apoA1, apoE and HDL particles. ${ }^{32}$ LXR activation induces redistribution of ABCG1 from intracellular sites to the plasma membrane and in- creases cholesterol mass efflux to HDL. ${ }^{33}$ Second, LXRs regulate several apolipoproteins and lipidmodulating enzymes involved in cholesterol efflux and HDL remodeling. Both LXR isoforms promote the expression of the entire ApoE/C-I/C-II/C-IV gene cluster via two LXREs identified in the $\mathrm{ApoE}$ promoter. ${ }^{34}$ Interestingly, LXRs induce expression of apoE in macrophages and adipocytes, but not in liver. The phospholipid transfer protein (PLTP) transfers phospholipids from HDL to triglyceride-rich lipoproteins. LXR activators can increase the expression and activity of PLTP, promoting HDL synthesize. ${ }^{35}$ Cholesterol ester transfer protein (CETP) mediates the transfer of cholesterol esters from HDL to triglyceride-rich lipoproteins prior to their uptake by the liver. Both LXR $\alpha$ and LXR $\beta$ induce the expression of CETP. However, because of both beneficial and deleterious effects of CETP, the potential therapeutic impact of LXR up-regulation of CETP expression should be treated with caution. ${ }^{36}$ Lipoprotein lipase (LPL) is the rate-limiting enzyme for the hydrolysis of lipoprotein triglycerides, which can promote the maturation of HDL. It is induced by LXR in the liver and macrophages except adipose tissue. Third, LXRs stimulate the mobilization of cholesterol from intracellular to the plasma membrane, and promote cholesterol efflux to extracellular receptors. Activation of LXR transcription factors may be atheroprotective by a novel mechanism that decreases macrophage receptor-independent, fluid-phage pinocytosis of atherogenic lipoproteins such as LDL, and LXRmediated decrease in macrophage pinocytosis of HDL may also be atheroprotective by increasing plaque HDL that is available to mediate RCT. 4,6,37

\section{LXRs and Bile Acid Synthesis, Excretion}

The liver-specific cholesterol $7 \alpha$-hydroxylase (CYP7A) is the rate-limiting enzyme in the classical pathway of bile acid synthesis, which was identified as the first direct target of LXRs in mice. In rodents, LXR $\alpha$ null mice exhibited massive amounts of choles- 
terol in livers, and LXR $\beta$ expression was unchanged. However, both wild-type and LXR $\beta$ null mice showed only slight increases in hepatic cholesterol levels. All the data suggest that $\mathrm{LXR} \alpha$ is the dominant isoform responsible for up-regulation of CYP7A in rodent. Nevertheless, human CYP7A expression is not regulated by LXR in vitro in HepG2 cells, which may explain their susceptibility to the development of hypercholesterolemia on a diet rich in cholesterol. ${ }^{38}$

LXRs may also induce hepatobiliary cholesterol secretion and fecal neutral sterol elimination. So far, the most likely target genes responsible for the LXRmediated activity are ABCG5 and ABCG8. These proteins form a heterodimer to pump cholesterol into bile, residing in the apical membrane of the hepatocyte. ${ }^{6}$

\section{LXRs and Triglyceride synthesis}

In addition to regulation of cholesterol homeostasis, LXR activation also induces the expression of genes involved in lipogenesis in the liver. Schultz et $\mathrm{al}^{39}$ showed that oral administration of T0901317 to mice activated the coordinate expression of lipogenesis and increased plasma triglyceride levels. The sterol regulatory element-binding protein-1c (SREBP-1c) in the liver, the major SREBP-1 isoform, is a direct LXR target gene. SREBP-1c can stimulate the transcription of lipogenic genes, including fatty acid synthase (FAS), acetyl-coA carbroxylase (ACC) and stearoyl CoA desaturase-1 (SCD-1). Besides, LXR activation can directly induce these lipogenic genes expression. Furthermore, LXR $\alpha$ but not LXR $\beta$ is the critical gene to regulate lipogenesis, facilitating the development of highly selective LXR modulators without undesirable lipogenic effects. ${ }^{40}$

\section{LXRs and Inflammation}

LXRs suppress an array of inflammatory genes as a result of macrophage activation (Fig 3). Macrophages are essential components for atherosclerosis. They can take up massive OX-LDL and induce the expression of inflammatory genes, leading to lesion initiation and

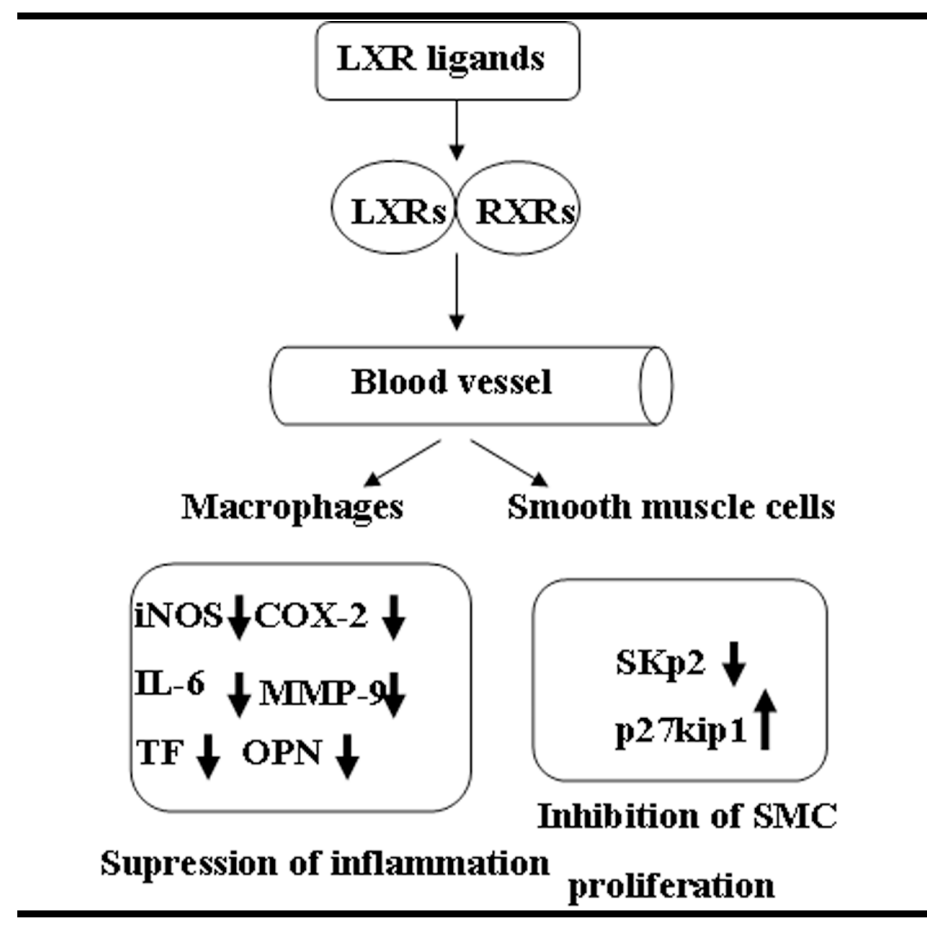

FIGURE 3. Vascular effects of LXRs LXRs heterodimerize with RXRs. Following their ligandinduced activation, LXRs inhibit inflammatory genes(iNOS, COX-2, IL-6, MMP-9, TF, OPN) expression in macrophage and suppress proliferation of SMCs(down-regulation of SKp2 and up-regulation of p27kip1).

progression. In vitro, LXR activators inhibit the expression of macrophage inflammatory genes, including inducible nitric oxide synthase (iNOS), cyclooxygenase-2 (COX-2), interleukin (IL-6), IL- $\beta$, monocyte chemoattractant protein-1 (MCP-1) and $\mathrm{MCP}-3$, in response to bacterial, tumor necrosis factor- $\alpha(\mathrm{TNF}-\alpha)$ or lipopolysaccharide stimulation. ${ }^{41-43}$ Subsequent studies showed that matrix metalloproteinase- 9 and tissue factor, which play a critical role in atherosclerotic plaque stability and thrombus formation following plaque rupture, could be suppressed by LXR ligands. ${ }^{44,45}$ Besides, LXR activation can inhibit cytokine-induced osteopontin expression in macrophages, a potential target for pharmacological intervention in atherosclerosis. ${ }^{46}$ The repression of inflammatory gene expression by LXR agonist treatment was mitigated in $\mathrm{LXR} \alpha^{(-/)}$, and LXR $\beta^{(-/-)}$compared with wild-type macrophages, but 
was completely abolished in $\mathrm{LXR} \alpha^{(-/)} \mathrm{LXR} \beta^{(-/)}$mice, suggesting that both LXR isoforms possess antiinflammatory activity. In vivo, LXR agonists reduce inflammation in both irritant and allergic contact models of dermatitis. LXR activation can suppress inflammatory genes expression in the aortas of atherosclerotic mice. ${ }^{47}$

On the other hand, LXR agonists enhance the expression of TNF- $\alpha$. However, since LXR activation appears not to induce other proinflammatory cytokines involved in the inflammatory immune response, it is possible that specific LXR-mediated stimulation of TNF- $\alpha$ expression may reduce atherosclerotic smooth muscle cells, form cells and infiltrating $\mathrm{T}$ cells.

The key mechanism for anti-inflammatory effects of LXRs appears to involve antagonism of NF- $\kappa B$ signaling. NF- $\kappa \mathrm{B}$ and these inflammatory genes mentioned above don't have LXREs in the proximal promoters, so trans-repression of NF- $\mathrm{NB}$ by LXR is essential. However, the precise mechanism how LXRs block NF- $\kappa$ B signaling is unknown., 9,48

\section{LXRs and the Immune System}

Current studies have demonstrated that several microbial pathogens could promote foam cell formation and accelerate lesion development, which is associated with LXR-dependent cholesterol metabolism. The innate immune system recognizes conserved motifs found in microbes by so-called pattern recognition receptors, including Toll-Like Receptors (TLR3 and TLR4), which can reduce the expression of LXR target genes. LXR-TLR cross-talk is independent of NF$\kappa \mathrm{B}$, but mediated by another transcription factor, interferon regulatory factor3, which is also implicated in the interferon response. Recently, it has been demonstrated that $48 \mathrm{~h}$ pre-treatment with LXR agonists leads to an increase in TLR4 expression in human macrophages, resulting in increased secretion pf cytokines that activate an immune adaptive inflammatory response. ${ }^{49}$ These findings highly emphasize the abil- ity of LXRs to integrate inflammatory and metabolic signaling. 50

In addition, mice devoid of both LXRs are more susceptible to microbial infections, developing higher bacterial burdens with accelerated rates of macrophage apoptosis. Valledor ${ }^{48}$ showed that activation of LXR inhibited macrophage apoptosis in response to apoptotic stimuli and infection. Subsequently, it was found that LXR could induce the expression of the anti-apoptotic gene Api6 (also known as Aim and Spa). ${ }^{51,52}$ Interestingly, LXR $\alpha^{(-/)}$mice but not LXR $\beta^{(-/-)}$ mirror the susceptibility of $\operatorname{LXR} \alpha^{(-/)} \operatorname{LXR} \beta^{(-/)}$mice, indicating that $\mathrm{LXR} \alpha$ is the major functional isoform in innate immunity. Hence, the study of LXR function in macrophages and other immune cells is unraveling previously unrecognized links between immunity and metabolism. ${ }^{8,49,52}$

\section{LXRs and Smooth Muscle Cells}

Proliferation of smooth muscle cells (SMCs) plays an important role in the pathogenesis of the late stage of atherosclerosis. Both LXR isoforms express in primary SMCs (Fig 3). Blaschke et $\mathrm{al}^{53}$ showed that, in human coronary SMCs, LXR activation could inhibit mitogen-induced SMC proliferation by preventing G1 to $\mathrm{S}$ phase progression of the cell cycle. Furthermore, the S phage kinase-associated protein 2 (Skp2), which could degrade the cyclin-dependent kinase inhibitor p27Kip1, was identified as the target gene of LXR. Additionally, LXR ligands reduced neointima formation following balloon angioplasty of the rat artery in vivo by increasing $\mathrm{p} 27 \mathrm{Kip} 1$ expression. ${ }^{53-55}$

To repress SMCs proliferation, LXR activation in SMCs can also induce several macrophage LXR target genes expression. It has been reported that LXR activation increases the expression of ABCA1 and ABCG1 in human airway SMCs, promoting cholesterol RCT and reducing the accumulation of intracellular cholesterol. Hence, the antiproliferative effects of LXRs on SMCs are important for prevention of development of atherosclerosis. ${ }^{56}$ 


\section{LXRs and Atherosclerosis}

Atherosclerosis is a chronic inflammatory state within the arterial wall characterized by alterations in lipid metabolism. As mentioned above, LXRs could regulate cholesterol metabolism as well as suppress inflammatory genes expression and SMCs proliferation, thus it is predicted that LXR activation can prevent the development of atherosclerosis. ${ }^{57,58}$ Joseph et $\mathrm{al}^{59}$ demonstrated that the synthetic LXR agonist GW3965 led to an approximately 50\% reduction in lesion size in both LDLR-deficient and apoE-deficient male mice with a high fat diet, two murine models of atherosclerosis. Terasaka et al ${ }^{60}$ reported that another LXR agonist T0901317 reduced the lesion area by $70 \%$ in LDLR-deficient mice with a high cholesterol diet. The expression of ABCA1 and ABCG1 were increased while the inflammatory genes were inhibited. In contrast, the levels of lipids in plasma were not altered. Furthermore, macrophage-specific loss of LXRs achieved by transplantation of bone marrow from $\operatorname{LXR} \alpha^{(-/)} \operatorname{LXR} \beta^{(-/)}$mice into either apo $E^{(-/)}$or LDLR $^{(--)}$mice resulted in an increase in lesion size and aggravated atherosclerosis, mainly through their effect on macrophage cholesterol efflux and the intravascular inflammatory reaction rather than by modulating the lipid profile. Additionally, transplantation of LXR-null bone barrow to LDLR ${ }^{(--)}$mice abolished the antiatherosclerotic effect of T0901317, which indicated that macrophage LXRs are essential for the antiatherosclerotic effect of LXR agonists. ${ }^{61,62}$ Current studies demonstrated that LXR agonists led to regression of atherosclerosis in preexisting lesions, contributing to the fact that most humans presenting with signs of cardiovascular disease already had substantial lesion development. ${ }^{63}$ These findings suggest that LXR activation exerts pleiotropic antiatherosclerotic effects. Meanwhile, it is emphasized that the macrophage LXR pathway is an attractive target for intervention in cardiovascular disease. ${ }^{63,64}$
Teupser et al ${ }^{65}$ showed that transgenic overexpression of LXR $\alpha$ using a macrophage gene expression construct led to an increase of cholesterol efflux from macrophages, a down-regulation of proinflammatory response, and a reduction of atherosclerosis. Transgenic expression of LXR $\alpha$ was primarily directed into macrophages, and animals did not show the attendant side-effects usually seen with generalized LXR activation by synthetic LXR agonists, so macrophage overexpression of LXR $\alpha$ might be useful as a therapeutic principle for the prevention of atherosclerosis.

\section{LXR Agonists for Atherosclerosis}

The antiatherosclerotic ability of LXRs makes them attractive targets for drugs developed for the treatment of cardiovascular disease. The first generation of nonselective synthetic ligands inhibited atherosclerosis in mice, but increased hepatic lipogenesis and plasma triglyceride levels, induction of proinflammatory cytokines such as TNF- $\alpha$ in macrophages. Bradley et al ${ }^{66}$ demonstrated that treatment of LXR $\alpha^{(-/)} \mathrm{Apoe}^{(--)}$ mice with synthetic LXR ligand ameliorated the cholesterol overload phenotype and reduces atherosclerosis. Their observations indicated that the pursuit of LXR $\beta$-specific agonist ligands for the treatment of atherosclerosis may prove to be fruitful.

The nonsteroidal compounds T0901317 and GW3965 are two common and important agonists of LXRs. Both compounds can increase rate of RCT and improve cholesterol homeostasis in mice. Furthermore, both agonists induce ABCA1 expression to similar extents in the small bowel, but in liver, T0901317 induces FAS and triglyceride generation while GW3965 has limited effects. However, there are other contradictory researches in vivo, so it is not easy to define GW3965 as a selective agonist regulating non-hepatic genes and improving cholesterol metabolism. Therefore, a new LXR ligand is needed without these side effects. ${ }^{67-69}$

Designing selective ligands is one possible approach. Both LXR isoforms promote cholesterol RCT 
and have anti-inflammatory ability. However, LXR $\alpha$ is the predominant gene in the liver to regulate triglyceride synthesis. Plasma triglyceride levels and the expression of hepatic multiple enzymes of fatty acid synthesis were reduced in LXR $\alpha$-deficient mice. Administration of a nonselective LXR agonists to LXR $\alpha$ deficient mice reduces whole-body cholesterol levels and atherosclerosis without causing hepatic steatosis, so LXR $\beta$ selective agonists may be the ideal antiatherosclerotic drugs. ${ }^{70,71}$ Nevertheless, the crystal structure of the ligand-binding domains of LXR $\alpha$ and LXR $\beta$ indicates that binging pockets are virtually identical, making it difficult to achieve highly selective agonists. ${ }^{72}$

The development of selective estrogen receptor modulators indicates the feasibility to design nuclear receptor ligands that function as agonists in one cell type but as antagonists in others depending on the coregulator levels present. ${ }^{72}$ Therefore, designing LXR modulators that act as agonist in macrophages and induce cholesterol efflux, but which act as antagonists of lipogenesis in the liver, is another critical and attractive approach. Furthermore, the crystal structure of LXR, with a large ligand-binding domain, makes it possible to identify LXR modulators. Two synthetic steroidal LXR agonists, ATI-829 and DMHCA, can be defined as good candidates for drug development by selectively activating, in mice, LXR target genes in certain tissues but not genes involved in liver lipogenesis.

Mice and humans have different gene expressions in response to LXR activation. Genes involved in bileacid production, innate immune response, and hepatic lipogenesis are regulated differently in mice and humans. Hence, any LXR-associated therapy needs to be tested in animals which are more similar in their metabolic pathways to humans. So far, none have been tested in humans. Attention should be paid to important species-differences with respect to the genes regulated by LXRs. $4,6,73$

\section{Conclusion}

The versatile antiatherosclerotic effects of LXRs provide possibilities for the development of a novel class of therapeutic drugs to treat atherosclerosis and cardiovascular diseases. However, due to the undesirable effects caused by first-generation LXR agonists, LXR $\beta$-selective agonists and selective LXR modulators need to be developed. Besides, the speciesspecific LXR regulation should not be ignored. In all, further research on the molecular mechanism of LXR is needed, which may facilitate treatment of clinical cardiovascular disease with more suitable drugs.

\section{Acknowledgments}

This work was supported by a grant from Jiangsu Province's Outstanding Medical Academic Leader program (No. LJ200610).

\section{References}

1. Rader DJ, Daugherty A. Translating molecular discoveries into new therapies for atherosclerosis. Nature 2008;451:1904-13.

2. Libby P. Inflammation in atherosclerosis. Nature 2002;420:868-74.

3. Lusis AJ. Atherosclerosis. Nature 2000;407:233-41.

4. Lala DS. The liver X receptors. Curr Opin Investig Drugs 2005;6:934-43.

5. Zelcer N, Tontonoz P. Liver X receptors as integrators of metabolic and inflammatory signaling. J Clin Invest 2006;116:607-14.

6. Nomiyama T, Bruemmer D. Liver X receptors as therapeutic targets in metabolism and atherosclerosis. Curr Atheroscler Rep 2008;10:88-95.

7. Tontonoz P, Mangelsdorf DJ. Liver X receptor signaling pathways in cardiovascular disease. Mol Endocrinol 2003; 17:985-93.

8. Fiévet C, Staels B. Liver X receptor modulators: effects on lipid metabolism and potential use in the treatment of atherosclerosis. Biochem Pharm 2009:77:1316-27.

9. Cha JY, Repa JJ. The liver X receptor (LXR) and hepatic lipogenesis. The carbohydrate-response elementbinding protein is a target gene of LXR. J Biol Chem 2007;282:743-51. 
10. Repa JJ, Mangelsdorf DJ. The liver X receptor gene team: potential new players in atherosclerosis. Nat Med 2002;8:1243-8.

11. Geyeregger R, Zeyda M, Stulnig TM. Liver X receptors in cardiovascular and metabolic disease. Cell Mol Life Sci 2006;63:524-39.

12. Lala DS. Liver $X$ receptors and atherosclerosis. IDrugs 2004;7:563-9.

13. Willy PJ, Umesono K, Ong ES, Evans RM, Heyman RA, Mangelsdorf DJ. LXR, a nuclear receptor that defines a distinct retinoid response pathway. Genes Dev 1995;9:1033-45.

14. Miller A, Crumbley C, Prufer K. The N-terminal nuclear localization sequences of liver $\mathrm{X}$ receptors alpha and beta bind to importin alpha and are essential for both nuclear import and transactivating functions. Int $\mathrm{J}$ Biochem Cell Biol 2009:41:834-43.

15. Alberti S, Steffensen KR, Gustafsson JA. Structural characterisation of the mouse nuclear oxysterol receptor genes LXR alpha and LXR beta. Gene 2000;243:93-103.

16. Goodwin BJ, Zuercher WJ, Collins JL. Recent advances in liver $\mathrm{X}$ receptor biology and chemistry. Curr Top Med Chem 2008;8:781-91.

17. Villacorta L, Garcia Barrio MT, Chen YE. Transcriptional regulation of peroxisome proliferator-activated receptors and liver X receptors. Curr Atheroscler Rep 2007;9:230-7.

18. Barish GD. Peroxisome proliferator-activated receptors and liver $\mathrm{X}$ receptors in atherosclerosis and immunity. J Nutr 2006;136:690-4.

19. Michael LF, Schkeryantz JM, Burris TP. The pharmacology of LXR. Mini Rev Med Chem 2005;5:729-40.

20. Kalaany NY, Mangelsdorf DJ. LXRS and FXR: the yin and yang of cholesterol and fat metabolism. Annu Rev Physiol 2006;68:183-9.

21. Ricote M, Valledor AF, Glass CK. Decoding transcriptional programs regulated by PPARs and LXRs in the macrophage: effects on lipid homeostasis, inflammation, and atherosclerosis. Arterioscler Thromb Vasc Biol 2004;24:230-9.

22. Papadopoulos V. Cholesterol homeostasis and infertility: the liver X receptor connection. Endocrinology 2005; 146:2517-8.

23. Millatt LJ, Bocher V, Fruchart JC, Staels B. Liver X receptors and the control of cholesterol homeostasis: potential therapeutic targets for the treatment of atherosclerosis. Biochimica et Biophysica Acta (BBA) - Molecular and Cell Bio 2003;1631:107-18.

24. Ulven SM, Dalen KT, Gustafsson JA, Nebb HI. LXR is crucial in lipid metabolism. Prostaglandins Leukot Essent Fatty Acids 2005;73:59-63.
25. Edwards PA, Kast HR, Anisfeld AM. BAREing it all: the adoption of LXR and FXR and their roles in lipid homeostasis. J Lipid Res 2002;43:2-12.

26. Repa JJ, Berge KE, Pomajzl C, Richardson JA, Hobbs $\mathrm{H}$, Mangelsdorf DJ. Regulation of ATP-binding cassette sterol transporters ABCG5 and ABCG8 by the liver $\mathrm{X}$ receptors alpha and beta. J Biol Chem 2002;277:18793-800.

27. Edwards PA, Kennedy MA, Mak PA. LXRs: oxysterolactivated nuclear receptors that regulate genes controlling lipid homeostasis. Vascul Pharmacol 2002;38:249-56.

28. Altmann SW, Davis HR, Zhu LJ, et al. Niemann-Pick C1 Like 1 protein is critical for intestinal cholesterol absorption. Science 2004;303:1201-4.

29. Duval C, Touche V, Tailleux A, et al. Niemann-Pick C1 like 1 gene expression is down-regulated by LXR activators in the intestine. Biochem Biophys Res Commun 2006;340:1259-63.

30. Tang W, Ma Y, Jia L, Ioannou YA, Davies JP, Yu L. Niemann-Pick C1-like 1 is required for an LXR agonist to raise plasma HDL cholesterol in mice. Arterioscler Thromb Vasc Biol 2008;28:448-54.

31. Rigamonti E, Chinetti GG, Staels B. Regulation of macrophage functions by PPAR-alpha, PPAR-gamma, and LXRs in mice and men. Arterioscler Thromb Vasc Biol 2008;28:1050-9.

32. Beyea MM, Heslop CL, Sawyez CG, et al. Selective up-regulation of LXR-regulated genes ABCA1, ABCG1, and APOE in macrophages through increased endogenous synthesis of 24(S),25-epoxycholesterol. J Biol Chem 2007;191:11-21.

33. Wang N, Ranalletta M, Matsuura F, Peng F, Tall AR. LXR-induced redistribution of ABCG1 to plasma membrane in macrophages enhances cholesterol mass efflux to HDL. Arterioscler Thromb Vasc Biol 2006;26:1310-6.

34. Mak PA, Laffitte BA, Desrumaux C, et al. Regulated expression of the apolipoprotein E/C-I/C-IV/C-II gene cluster in murine and human macrophages. A critical role for nuclear liver X receptors alpha and beta. J Biol Chem 2002;277:31900-8.

35. Mak PA, Kast HR, Anisfeld AM, Edwards PA. Identification of PLTP as an LXR target gene and apoE as an FXR target gene reveals overlapping targets for the two nuclear receptors. J Lipid Res 2002;43:2037-41.

36. Luo Y, Tall AR. Sterol upregulation of human CETP expression in vitro and in transgenic mice by an LXR element. J Clin Invest 2000;105:513-20.

37. Gupta S, Pandak WM, Hylemon PB. LXR alpha is the dominant regulator of CYP7A1 transcription. Biochem Biophys Res Commun 2002;293:338-43. 
38. Joseph SB, Tontonoz P. LXRs: new therapeutic targets in atherosclerosis?. Curr Opin Pharmacol 2003;3:192-7.

39. Schultz JR, Tu H, Luk A, et al. Role of LXRs in control of lipogenesis. Genes Dev 2000;14:2831-8.

40. Grefhorst A, Elzinga BM, Voshol PJ, et al. Stimulation of lipogenesis by pharmacological activation of the liver X receptor leads to production of large, triglyceride-rich very low density lipoprotein particles. J Biol Chem 2002;277:34182-90.

41. Bruemmer D, Law RE. Liver x receptors: potential novel targets in cardiovascular diseases. Curr Drug Targets Cardiovasc Haematol Disord 2005;5:533-40.

42. Bradley MN, Tontonoz P. Lesion macrophages are a key target for the antiatherogenic effects of LXR agonists. Arterioscler Thromb Vasc Biol 2005;25:10-11.

43. Joseph SB, Castrillo A, Laffitte BA, Mangelsdorf DJ, Tontonoz P. Reciprocal regulation of inflammation and lipid metabolism by liver X receptors. Nat Med 2003;9:213-9.

44. Castrillo A, Joseph SB, Marathe C, Mangelsdorf DJ, Tontonoz P. Liver X receptor-dependent repression of matrix metalloproteinase- 9 expression in macrophages. J Biol Chem 2003;278:10443-9.

45. Terasaka N, Hiroshima A, Ariga A, et al. Liver X receptor agonists inhibit tissue factor expression in macrophages. FEBS J 2005;272:1546-56.

46. Ogawa D, Stone JF, Takata Y, et al. Liver x receptor agonists inhibit cytokine-induced osteopontin expression in macrophages through interference with activator protein-1 signaling pathways. Circ Res 2005;96:e59-e67.

47. Fowler AJ, Sheu MY, Schmuth M, et al. Liver X receptor activators display anti-inflammatory activity in irritant and allergic contact dermatitis models: liver-Xreceptor-specific inhibition of inflammation and primary cytokine production. J Invest Dermatol 2003; 130:246-55.

48. Bocher V, Millatt LJ, Fruchart JC, Staels B. Liver X receptors: new players in atherogenesis? Curr Opin Lipidol 2003;14:137-43.

49. Fintaine C, Rigamonti E, Nohara A, et al. Liver X receptor activation potentiates the lipopolysaccharide response in human macrophages. Circ Res 2007:101:40-9.

50. Ogawa S, Lozach J, Benner C, et al. Molecular determinants of crosstalk between nuclear receptors and toll-like receptors. Cell 2005;122:707-21.

51. Joseph SB, Bradley MN, Castrillo A, et al. LXRdependent gene expression is important for macrophage survival and the innate immune response. Cell 2004;119:299-309.
52. Arai S, Shelton JM, Chen M, et al. A role for the apoptosis inhibitory factor AIM/Spalpha/Api6 in atherosclerosis development. Cell Metab 2005;1:201-13.

53. Blaschke F, Leppanen O, Takata Y, et al. Liver X receptor agonists suppress vascular smooth muscle cell proliferation and inhibit neointima formation in balloon-injured rat carotid arteries. Circ Res 2004;95:110-23.

54. Delvecchio CJ, Bilan P, Radford K, et al. Liver X receptor stimulates cholesterol efflux and inhibits expression of proinflammatory mediators in human airway smooth muscle cells. Mol Endocrinol 2007;21:1324-34.

55. Pagano M. Control of DNA synthesis and mitosis by the Skp2-p27-Cdk1/2 axis. Mol Cell 2004;14:414-6.

56. Davies JD, Carpenter KL, Challis IR, et al. Adipocytic differentiation and liver $\mathrm{x}$ receptor pathways regulate the accumulation of triacylglycerols in human vascular smooth muscle cells. J Biol Chem 2005;280:3911-9.

57. Lund EG, Menke JG, Sparrow CP. Liver X receptor agonists as potential therapeutic agents for dyslipidemia and atherosclerosis. Arterioscler Thromb Vasc Biol 2003;23:1169-77.

58. Li AC, Glass CK. PPAR- and LXR-dependent pathways controlling lipid metabolism and the development of atherosclerosis. J Lipid Res 2004;45:2161-73.

59. Joseph SB, McKilligin E, Pei L, et al. Synthetic LXR ligand inhibits the development of atherosclerosis in mice. Proc Natl Acad Sci U S A 2002;99:7604-9.

60. Terasaka N, Hiroshima A, Koieyama T, et al. T0901317, a synthetic liver X receptor ligand, inhibits development of atherosclerosis in LDL receptordeficient mice. FEBS Lett 2003;536:6-11.

61. Handschin C, Meyer UA. Regulatory network of lipidsensing nuclear receptors: roles for CAR, PXR, LXR, and FXR. Arch Biochem Biophys 2005;433:387-92.

62. Kovanen PT, Pentikainen MO. Pharmacological evidence for a role of liver $\mathrm{X}$ receptors in atheroprotection. FEBS Lett 2003;536:3-5.

63. Collins JL. Therapeutic opportunities for liver X receptor modulators. Curr Opin Drug Discov Devel 2004;7:692-702.

64. Lee CH, Plutzky J. Liver X receptor activation and high-density lipoprotein biology: a reversal of fortune? Circulation 2006;113:5-8.

65. Teupser D, Kretzschmar D, Tennert C et al. Effect of macrophage overexpression of murine liver $\mathrm{X}$ receptoralpha (LXR-alpha) on atherosclerosis in LDL-receptor deficient mice. Arterioscler Thromb Vasc Biol 2008:28:2009-15.

66. Bradley MN, Hong C, Chen M, et al. Ligand activation of LXR beta reverses atherosclerosis and cellular cho- 
lesterol overload in mice lacking LXR alpha and apoE. J Chin Invest 2007;117:2337-46.

67. Fievet C, Staels B. Liver X receptor modulators: effects on lipid metabolism and potential use in the treatment of atherosclerosis. Biochem Pharmacol 2009:77:1316-27.

68. Wójcicka G, Jamroz-Wiśniewska A, Horoszewicz K, Bełtowski J. Liver X receptors (LXRs). Part I: structure, function, regulation of activity, and role in lipid metabolism. Postepy Hig Med Dosw (Online) 2007:61:736-59.

69. Jamroz-Wiśniewska A, Wójcicka G, Horoszewicz K, Bełtowski J. Liver X receptors (LXRs). Part II: nonlipid effects, role in pathology, and therapeutic implications. Postepy Hig Med Dosw (Online) 2007:61:760-85.

70. Lund EG, Peterson LB, Adams AD, et al. Different roles of liver X receptor alpha and beta in lipid metabolism: effects of an alpha-selective and a dual agonist in mice deficient in each subtype. Biochem Pharmacol 2006;71:453-63.
71. Quinet EM, Savio DA, Halpern AR, et al. Liver X receptor (LXR)-beta regulation in LXR alpha-deficient mice: implications for therapeutic targeting. Mol Pharmacol 2006;70:1340-9.

72. Gustafsson JA. Therapeutic potential of selective estrogen receptor modulators. Curr Opin Chem Biol 1998;2:508-11.

73. Scott J. The liver X receptor and atherosclerosis. N Engl J Med 2007:357:2195-7.

Correspondence to:

Dr. You Sheng Li

Jinling Hospital, Nanjing University School of Medicine, 305 East Zhongshan Road, Nanjing 210002, China

E-mail: liys@medmail.com.cn 